\title{
Balanced Intersystem Crossing in lodinated Silicon-Fluoresceins Allows New Class of Red Shifted Theranostic Agents
}

\author{
Sultan Cetin, Zubeyir Elmazoglu, Osman Karaman, Hande Gunduz, Gorkem Gunbas,* \\ and Safacan Kolemen*
}

Cite This: ACS Med. Chem. Lett. 2021, 12, 752-757

Read Online

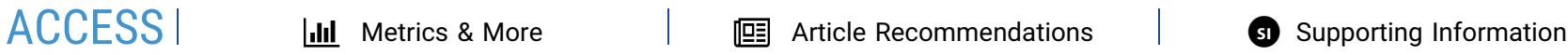

ABSTRACT: Iodination of the silicon-fluorescein core revealed a new class of highly cytotoxic, red-shifted and water-soluble photosensitizer (SF-I) which is also fairly emissive to serve as a theranostic agent. Singlet oxygen generation capacity of SF-I was evaluated chemically, and up to $45 \%$ singlet oxygen quantum yield was reported in aqueous solutions. SF-I was further tested in triple negative breast (MDA MB-231) and colon (HCT-116) cancer cell lines, which are known to have limited chemotherapy options as well as very poor prognosis. SF-I induced efficient singlet oxygen generation and consequent photocytotoxicity in both cell lines

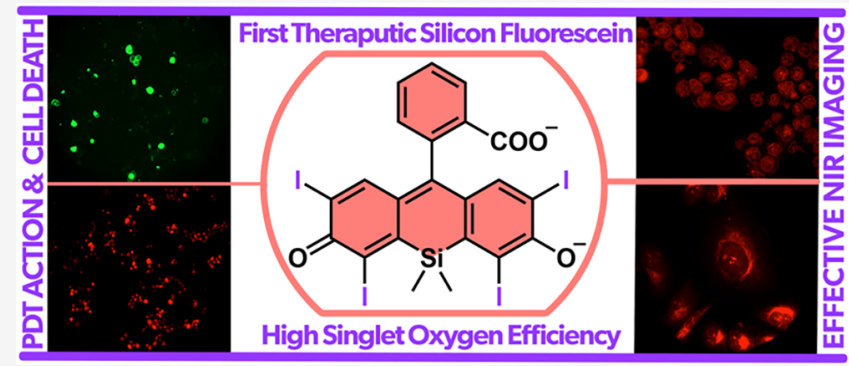
upon light irradiation with a negligible dark toxicity while allowing cell imaging at the same time. SF-I marks the first ever example of a silicon xanthene-based photosensitizer and holds a lot of promise as a small-molecule-based theranostic scaffold.

KEYWORDS: Photodynamic therapy, cancer, theranostic, silicon-fluorescein, fluorescence imaging

$\mathrm{P}$ hotodynamic therapy (PDT), which involves the generation of cytotoxic reactive oxygen species (ROS) through interaction of a photosensitizer (PS), light, and molecular oxygen $\left({ }^{3} \mathrm{O}_{2}\right)$, is a developing treatment methodology for a wide variety of cancer types. ${ }^{1,2}$ PDT has remarkable advantages over conventional therapies such as activation of the immune system, minimal invasiveness, opportunities for repeated application without initiating drug resistance, and a fast healing process with little or no scar formation. ${ }^{1-3}$ Additionally, the technique offers localized treatment as singlet oxygen $\left({ }^{1} \mathrm{O}_{2}\right)$ has a short lifetime in aqueous medium and the excitation light can be precisely delivered to the tumor region, leaving most of the healthy cells unaffected. ${ }^{1,3,4}$ However, there is a major obstacle that PDT agents have to overcome to receive widespread acceptance in clinical studies, which is the limited penetration depth of irradiation light through tissues. ${ }^{3,5}$ It is a known fact that red/near-IR excitation light has the ability to penetrate more deeply into the target tissue while being less harmful to cells. ${ }^{6-8}$ This basically extends the scope of PDT by enabling the treatment of deep tumors. In this direction, a large amount of effort has been devoted to design red-shifted PSs. ${ }^{9-20}$ Nevertheless, most of the current examples are either based on the first-generation hydrophobic PSs, which require significant synthetic efforts to implement water solubility, or some other hydrophilic PSs having dark toxicity and photostability issues. ${ }^{2,21,22}$

Another emerging trend in the design of new generation PDT agents is to combine therapeutic action and fluorescent imaging. These so-called theranostic agents have attracted great interest in recent years as they allow monitoring both location of tumors and drugs as well as the efficacy of the treatment. $^{23,24}$ Undoubtedly, red-shifted agents are also highly attractive for theranostic applications. A majority of the PDT theranostics employ NIR-activated inorganic nanoparticlebased approaches, ${ }^{25}$ which tend to exhibit long-term toxicity, long retention time, challenges in large-scale synthesis, and lack of biodegradability. On the other side, small-molecule-based designs are substantially limited to few cores that possess the aforementioned limitations. ${ }^{21}$ Thus, development of new PS skeletons that are intrinsically red-shifted and water-soluble are still highly required in the scope PDT theranostics.

Fluorescein derivatives are among the most known and widely used fluorophores due to their unique properties such as water solubility and high extinction coefficients as well as high fluorescence quantum yields. ${ }^{26-28}$ Brominated (ex., eosin yellow) or iodinated (ex., rose bengal, erythrosin B) ${ }^{29}$ fluorescein derivatives have also been utilized as important PDT agents because they show high singlet oxygen quantum yields as in the case of other heavy atom incorporated

Received: January 10, 2021

Accepted: February 22, 2021

Published: March 16, 2021 
fluorophores. ${ }^{10,30-32}$ Although fluorescein-based PSs are long known and recognized as reference PSs, these agents absorb light in the visible region of the spectrum (around $500 \mathrm{~nm}$ ), which is simply out of the therapeutic window. ${ }^{29}$ In 2011, Nagano and coworkers introduced a red-shifted analogue of fluorescein by replacing the endocyclic oxygen atom in the xanthene moiety with a silicon. ${ }^{33}$ Change of oxygen to dimethylsilyl group accounts for approximately $100 \mathrm{~nm}$ red shift in both absorption and emission maxima. Silicon substituted fluorescein (silicon-fluorescein, SF) derivatives retain all unique properties of fluoresceins while exhibiting highly beneficial red-shifted absorption and emission signals. Under these circumstances, it is no surprise to see that siliconfluoresceins have been employed in many different bioimaging studies during the past decade (Figure 1). ${ }^{34,35}$ Silicon-

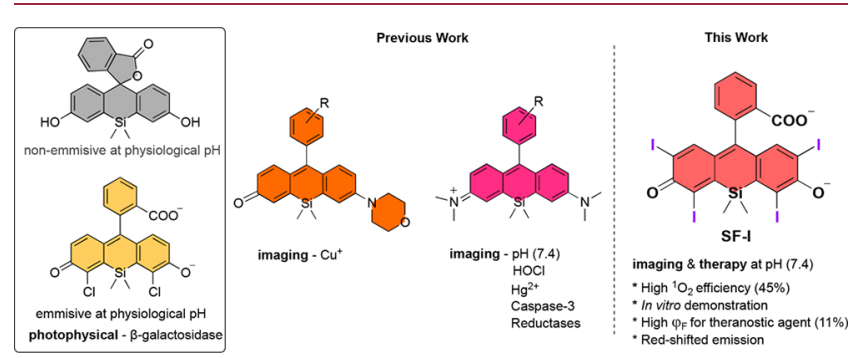

Figure 1. Literature examples of silicon-fluoresceins and highlights of this work.

fluoresceins also hold all critical features that one would expect from a PS; however, they have not yet been utilized in PDT applications. Herein, we report for the first time the conversion of silicon-fluorescein core to a highly cytotoxic PS (SF-I) (Figure 1) with significant fluorescence, which can serve as a water-soluble and red-shifted theranostic core.

SF-I, an analogue of erythrosin B, bears four iodine atoms on the silicon xanthene core (SF) to facilitate effective heavy atom mediated ISC upon excitation. An elegant and fast approach to synthesis of the SF core has been recently reported by Lavis et al. ${ }^{36}$ The same methodology was followed to synthesize the SF core in four steps (Figure S1). While introduction of halogens to xanthene-based cores can be quite difficult when they are fully conjugated, for example in resorufin, ${ }^{37}$ the lactone form of silicon-fluorescein was found to be easily modified with iodine (Figure 2). In fact, introduction of just one iodine was proven

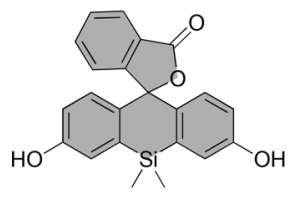

SF

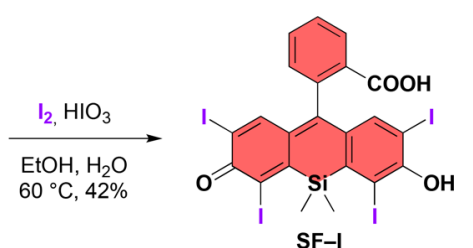

SF-I
Figure 2. Iodination of silicon-fluorescein.

difficult, and mixtures of higher iodinated derivatives were attained. Hence, the reaction conditions were modified to push the reaction toward tetra-iodination. The approach proved to be fruitful, and tetra-iodinated product was obtained in moderate yield.

After completing the synthesis, we first measured the absorption and fluorescence characteristics of SF-I in aqueous solutions under different $\mathrm{pH}$ values (Figure 3, Table 1). The parent SF core has the capability of forming intramolecular
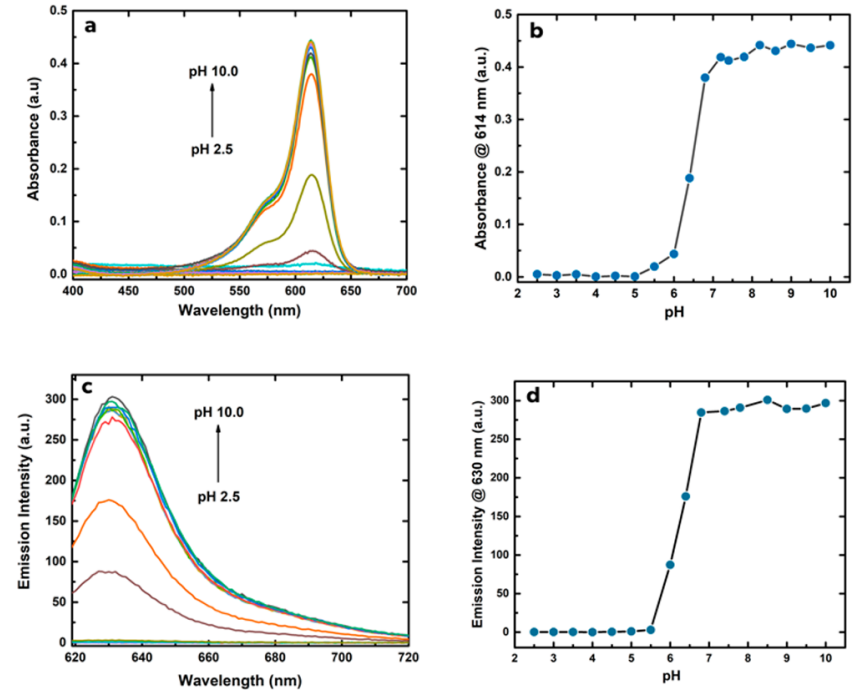

Figure 3. $\mathrm{pH}$ dependent absorption (a) and emission (c) spectra of SF-I $(5 \mu \mathrm{M})$ in PBS (pH 7.4, 0.5\% DMSO). Corresponding pH plots of absorbance at $614 \mathrm{~nm}(\mathrm{~b})$ and fluorescence at $630 \mathrm{~nm}(\mathrm{~d})$.

Table 1. Photophysical Properties and ${ }^{1} \mathrm{O}_{2}$ Quantum Yields of SF-I and SF

$\begin{array}{cccccc}\text { PS } & \lambda_{\text {abs }}(\mathrm{nm}) & \varepsilon\left(\mathrm{M}^{-1} \mathrm{~cm}^{-1}\right) & \lambda_{\text {ems }}(\mathrm{nm}) & \varphi_{\mathrm{F}}(\%) & \varphi_{\Delta}(\%)^{c} \\ \text { SF-I } & 614^{a} & 76500^{a} & 630^{a} & 11^{a, b} & 45 \pm 0.08^{a, d} ; \\ & & & & & 30 \pm 0.01^{a, e} \\ \text { SF } & 580^{f} & 110000^{f} & 598^{f} & 38^{f} & \text { n.d. }\end{array}$

${ }^{a}$ Measured in PBS buffer (pH 7.4, 0.5\% DMSO). ${ }^{b}$ Calculated via spectrophotometer with an integrated sphere detector. ${ }^{c}$ Methylene blue was used as a reference in PBS buffer $\left(\Phi_{\Delta}=0.52\right) .{ }^{38}{ }^{d}$ Upon irradiation with a $595 \mathrm{~nm}$ LED. ${ }^{e}$ Upon irradiation with a $630 \mathrm{~nm}$ LED. ${ }_{\text {Ref }} 39$, n.d.: not determined.

spirolactone in a $\mathrm{pH}$-dependent manner due to the presence of the carboxylic acid group on the benzene ring. SF is known to be predominantly in its neutral closed lactone form at physiological medium ( $\mathrm{pH} 7.4$ ), which results in a colorless and nonemissive agent owing to broken $\pi$-system on the xanthene moiety. ${ }^{39}$ It was previously shown that modifying the xanthene core of SF with electron withdrawing halogens such as chlorine (SF-Cl) and fluorine (SF-F) decreases the $\mathrm{p} K_{\mathrm{a}}$ values and yields a colorful and highly emissive agent as SF tends to stay in its open and deprotonated dianion form. ${ }^{39}$ In our case, SF-I exhibited similar $\mathrm{pH}$ dependency to SF-Cl and SF-F. No absorption and emission peaks were detected below $\mathrm{pH}$ 6, whereas a very sharp increase in both signals was observed between $\mathrm{pH} 6$ and 7 (Figure 3). Thus, at acidic pH values, SF-I forms intramolecular spirolactone as expected and becomes colorless as well as nonemissive. At $\mathrm{pH}$ 7.4, SF-I showed characteristic dianion (open-form) absorption and emission peaks centered at 614 and $630 \mathrm{~nm}$, respectively (Table 1), which are slightly red-shifted compared to dianions of SF, SF-Cl, and SF-F. ${ }^{39}$ This is quite promising as it infers that SF-I can serve as a PDT agent at physiological conditions. As expected, the fluorescence quantum yield of SF-I (11\%) at $\mathrm{pH} 7.4$ is lower than that of other SF derivatives due to the effective ISC (Table 1), which is known to compete with fluorescence relaxation pathway. However, it is still fairly emissive for bioimaging applications. ${ }^{2}$

Next, we wanted to demonstrate that SF-I can induce singlet oxygen generation, a primary cytotoxic agent of PDT action, 
upon light irradiation. To do so, a water-soluble trap molecule 2,2' -(anthracene-9,10-diyl)bis(methylene)dimalonic acid (ADMDA) and SF-I $(5 \mu \mathrm{M})$ were mixed in an oxygen saturated aqueous solution (0.5\% DMSO, PBS pH 7.4), and the mixture was irradiated initially with a $595 \mathrm{~nm}$ LED light $\left(9.83 \mathrm{~mW} / \mathrm{cm}^{2}\right)$. A gradual decrease in the ADMDA absorption at $380 \mathrm{~nm}$ was observed after each light irradiation as a result of $[4+2]$ cycloaddition of generated ${ }^{1} \mathrm{O}_{2}$ to the anthracene core (Figure $4 \mathrm{a}$ ). We further confirmed ${ }^{1} \mathrm{O}_{2}$
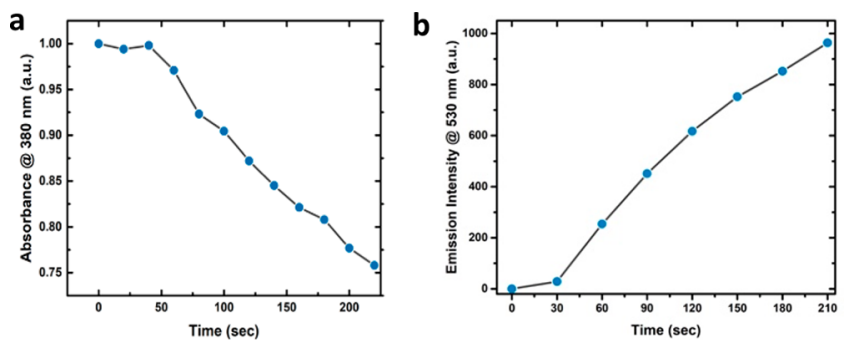

Figure 4. (a) Decrease in the absorption signal of ADMDA in PBS ( $\mathrm{pH} 7.4,0.5 \%$ DMSO) (during first $40 \mathrm{~s}$, the samples were kept in the dark) and (b) increase in the emission signal of SOSG upon irradiation of SF-I $(5 \mu \mathrm{M})$ with $595 \mathrm{~nm}$ LED light $\left(9.83 \mathrm{~mW} / \mathrm{cm}^{2}\right)$.

generation by using singlet oxygen sensor green (SOSG), which emits green emission at $530 \mathrm{~nm}$ upon reacting with ${ }^{1} \mathrm{O}_{2}$ selectively. After irradiating aqueous solutions of SF-I $(5 \mu \mathrm{M})$ in the presence of SOSG with an LED light (595 nm, 9.83 $\left.\mathrm{mW} / \mathrm{cm}^{2}\right)$, emission intensity of SOSG increased gradually (Figure $4 \mathrm{~b}$ ), which clearly indicates the presence of photosensitized singlet oxygen. ${ }^{1} \mathrm{O}_{2}$ quantum yield of SF-I was determined by using methylene blue $(\Phi \Delta=52 \%$ in PBS buffer $)^{38}$ as a reference PS and calculated as $45 \%$. The same trap experiments with ADMDA and SOSG were also repeated with a more red-shifted LED light $\left(630 \mathrm{~nm}, 24.3 \mathrm{~mW} / \mathrm{cm}^{2}\right)$ because SF-I has a broad absorption band ranging between 550 and $650 \mathrm{~nm}$ in aqueous solutions. In a similar way, decrease in the ADMDA absorption as well as the increase in the SOSG emission proved that $630 \mathrm{~nm}$ irradiation can also trigger ${ }^{1} \mathrm{O}_{2}$ formation (Figures S2, S4, and S5). Although the light dosage employed under $630 \mathrm{~nm}$ illumination is higher than that of 595 $\mathrm{nm},{ }^{1} \mathrm{O}_{2}$ quantum yield of SF-I (30\%) was found to be lower compared to $595 \mathrm{~nm}$ excitation as its absorption signal is stronger at $595 \mathrm{~nm}$. When the ADMDA trap experiment was repeated with SF upon $595 \mathrm{~nm}$ light irradiation, no ${ }^{1} \mathrm{O}_{2}$ generation was detected (Table 1, Figure S3). Photostability of SF-I was tested by monitoring the absorption and emission signals at 614 and $630 \mathrm{~nm}$, respectively, under continuous LED (595 and $630 \mathrm{~nm}$ ) irradiation for $2 \mathrm{~h}$ in PBS ( $\mathrm{pH} \mathrm{7.4,0.5 \%}$ DMSO). Only a very small decrease was observed in absorption signals, whereas no change in fluorescence peaks was detected, clearly suggesting high photostability (Figure S6).

After showing the ${ }^{1} \mathrm{O}_{2}$ generation chemically, photocytotoxicity of SF-I was examined by conventional MTT assay in triple negative breast (TNBC, MDA MB-231) and colorectal (HCT-116) cancers due to their complex prognosis and limited chemotherapeutic options. ${ }^{40,41}$ Cells were initially incubated with SF-I at concentrations ranging from 0 to $20 \mu \mathrm{M}$ and then irradiated either 1 or $2 \mathrm{~h}$ with two different LED sources (595 and $630 \mathrm{~nm}, 9.83$ and $24.3 \mathrm{~mW} / \mathrm{cm}^{2}$ ). Cell viabilities decreased gradually in a dose-dependent manner in both cancer cells upon both 595 and $630 \mathrm{~nm}$ irradiation with lower $\mathrm{IC}_{50}$ values in the case of $2 \mathrm{~h}$ irradiation, as expected (Figure 5, Table S1). Among two different LED sources, 595

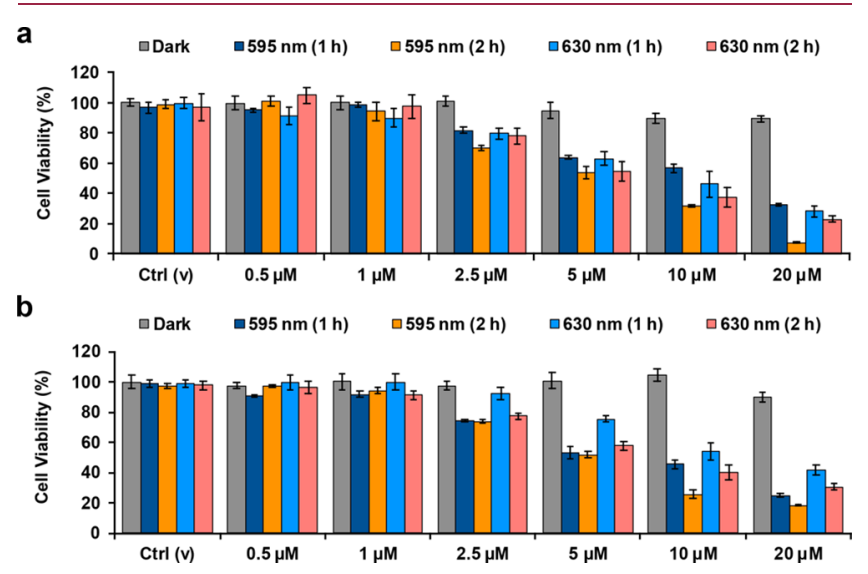

Figure 5. Cell viabilities of HCT-116 (a) and MDA MB-231 (b) cancer cells treated with the increasing concentrations $(0.5-20 \mu \mathrm{M})$ of SF-I either under dark conditions $(24 \mathrm{~h})$ or upon irradiation with LED light ( 595 or $630 \mathrm{~nm}$ ) for 1 or $2 \mathrm{~h}$, followed by 23 and $22 \mathrm{~h}$ dark, respectively. Ctrl (v): vehicle control. Data are presented as mean \pm $\mathrm{SD}(n=4)$.

$\mathrm{nm}$ irradiation was shown to be more effective in inducing cell death, which is in good correlation with ${ }^{1} \mathrm{O}_{2}$ quantum yields (Figure 5, Table S1). However, considering the better penetration ability of $630 \mathrm{~nm}$ light, it is notable to observe cell death in both cell lines with reasonable $\mathrm{IC}_{50}$ values upon $630 \mathrm{~nm}$ irradiation. No dark toxicity was detected in both cells as evidenced from the high cell viabilities when there is no light illumination. Thus, SF-I exhibited a comparable ${ }^{1} \mathrm{O}_{2}$ generation yield to standard PS methylene blue in aqueous solutions upon $595 \mathrm{~nm}$ excitation without showing inherent dark toxicity. ${ }^{42}$ Additionally, we confirmed that light sources did not cause any cytotoxicity during the course of irradiation (Figure 5). SF-I induced intracellular ROS generation was monitored in MDA MB-231 and HCT-116 cancer cells under confocal microscopy by employing a cell permeable ROS sensor, $2^{\prime}, 7^{\prime}$-dichlorofluorescein diacetate $\left(\mathrm{DCFH}_{2}-\mathrm{DA}\right)$, which emits strong green emission after oxidation by a reactive oxygen species. Irradiation of sensor and SF-I incubated cells with a $595 \mathrm{~nm}$ LED source resulted in a green emission, clearly suggesting effective ROS generation (Figure 6). When the cells were treated with $\mathrm{NaN}_{3}$, a singlet oxygen quencher, ${ }^{43}$ the green emission disappeared, which indicates that SF-I generates singlet oxygen as a primary cytotoxic agent during the PDT action (Figure 6). On the other side, the ROS sensor showed no detectable emission in the case of vehicle control and under dark conditions (Figure 6). Finally, cells were pretreated with $\mathrm{H}_{2} \mathrm{O}_{2}$ to check that the sensor works properly in the presence of ROS. In this positive control experiment, a green emission was retained in both cell lines unsurprisingly (Figure 6).

Cell death mechanism during the PDT action was also investigated by using green emitting annexin V-FITC (AV, detects early apoptotic cells) and red emitting propidium iodide (PI, detects late apoptotic and necrotic cells) stains. In this direction, MDA MB-231 and HCT-116 cells were incubated with SF-I $(5 \mu \mathrm{M})$. In each cell type, a group of cells was irradiated for $2 \mathrm{~h}$ with a $595 \mathrm{~nm}$ LED light and treated with AV and PI stains $30 \mathrm{~min}$ after PDT, while another group was kept under dark conditions. Both green and red 


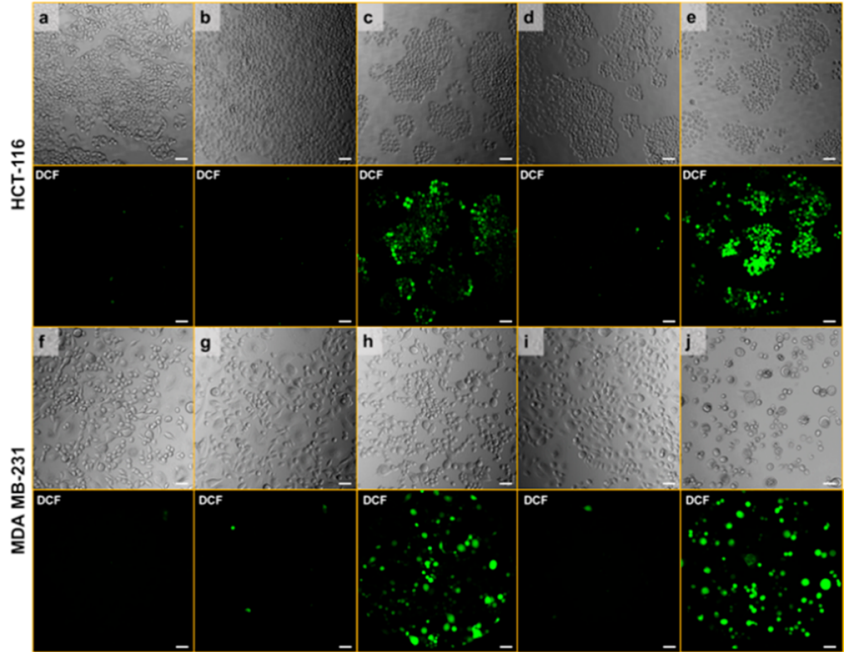

Figure 6. Intracellular ROS levels detected by $\mathrm{DCFH}_{2}$-DA staining in HCT-116 (a-e) and MDA MB-231 ( $\mathrm{f}-\mathrm{j})$ cells treated with DMSO $(0.5 \%)(\mathrm{a}, \mathrm{f})$ or SF-I $(5 \mu \mathrm{M})$ in the dark $(\mathrm{b}, \mathrm{g})$. SF-I treated cells were irradiated with LED light $(595 \mathrm{~nm})$ in the absence $(c, h)$ or presence (d, i) of $\mathrm{NaN}_{3}$ for $2 \mathrm{~h} . \mathrm{H}_{2} \mathrm{O}_{2}(500 \mu \mathrm{M}, 2 \mathrm{~h})$ treated cells were used as a positive control $(e, j)$. Scale bar: $50 \mu \mathrm{m}$.

emission were observed only in the irradiated cells, which supports the lack of dark toxicity and indicates that some cells undergo early apoptosis, but there is also another group of cells that initiates late apoptosis/necrosis at $30 \mathrm{~min}$ post-PDT (Figure 7). However, PI positive cells (with disrupted nuclei)

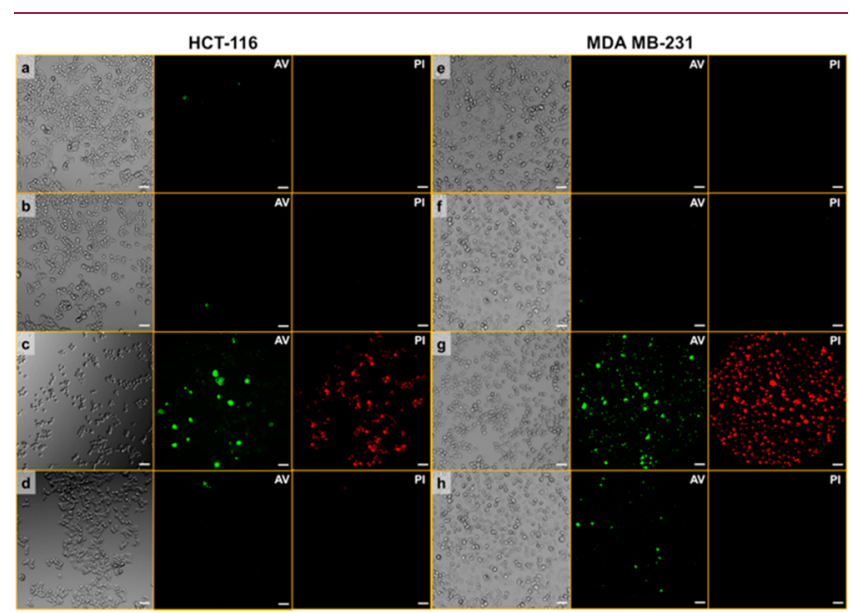

Figure 7. Confocal microscopy images of apoptosis and necrosis of HCT-116 $(\mathrm{a}-\mathrm{d})$ and MDA MB-231 $(\mathrm{e}-\mathrm{h})$ cells treated with DMSO $(0.5 \%)(a, e)$ or SF-I $(5 \mu \mathrm{M})$ under dark conditions (b, f). SF-I treated cells were irradiated with LED light $(595 \mathrm{~nm})$ in the absence (c, g) or presence (d, h) of $\mathrm{NaN}_{3}$ for $2 \mathrm{~h}$. After treatments, cells were stained with Annexin V-FITC (green) and PI (red) to monitor apoptotic or necrotic cells, respectively. Scale bar: $50 \mu \mathrm{m}$.

were relatively much higher than AV positive cells, which means that the cells tended to undergo necrosis rather than apoptosis. Treating cells with $\mathrm{NaN}_{3}$ dramatically suppressed the cell death even after $2 \mathrm{~h}$ of PDT action (Figure 7 ). This is additional evidence clearly showing that ${ }^{1} \mathrm{O}_{2}$ is the major cytotoxic agent.

Given that SF-I has a strong emission signal in aqueous solutions, we finally wanted to determine whether SF-I can be used to image cells. MDA MB-231 and HCT-116 cells were incubated with SF-I $(5 \mu \mathrm{M})$ for $2 \mathrm{~h}$ and washed prior to confocal imaging. Both cells displayed mostly cytosolic and rarely nuclear red emission, illustrating that SF-I permeates into the cells and gives a strong intracellular fluorescence signal despite it carrying four iodine atoms (Figure 8).

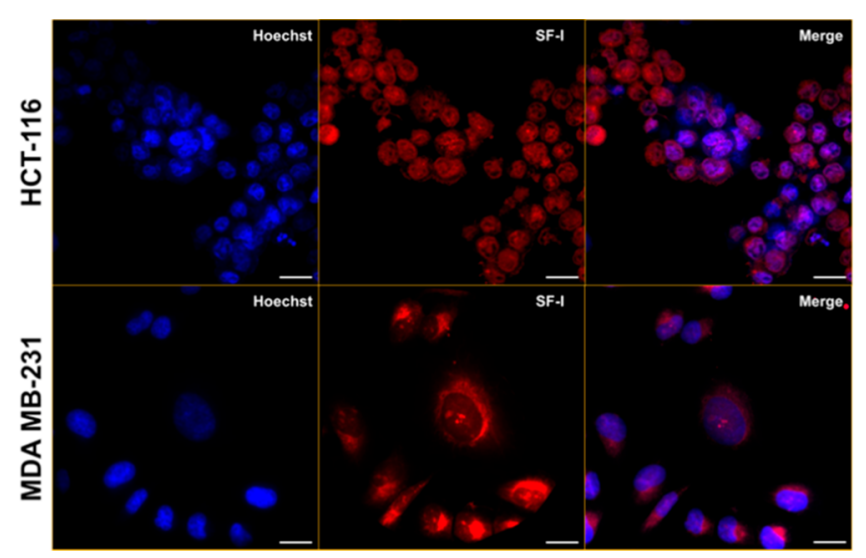

Figure 8. Confocal images of SF-I ( $5 \mu \mathrm{M})$ in HCT-116 (a) and MDA MB-231 (b) cancer cells after $2 \mathrm{~h}$ incubation. Blue, Hoechst 33342; red, SF-I. Scale bar: $20 \mu \mathrm{m}$.

To close, we have developed here for the first time an iodinated silicon-fluorescein (SF-I) that can serve as an effective red-shifted theranostic agent at physiological conditions. SF-I showed high ${ }^{1} \mathrm{O}_{2}$ quantum yields under both 595 and $630 \mathrm{~nm}$ irradiations, and its cytotoxicity was tested in two cancer cells with limited chemotherapy options. In vitro cell culture results clearly demonstrated that SF-I can induce cell death as a result of successful PDT action and at the same time can still act as a fluorophore. SF-I introduces a new class of easily accessible photosensitizers which hold promise toward the realization of image-guided PDT applications. SF-I addresses most of the chronic problems of the current PSs and displays properties desirable in a theranostic agent; it has high water solubility, high ${ }^{1} \mathrm{O}_{2}$ quantum yield in aqueous solutions, red-shifted absorption/emission signals, high photostability, and negligible dark toxicity. In addition, the SF-I core can be modified with different cage groups or targeting moieties as well as organelle directing units to design highly efficient cancer cell selective agents. Finally, $\pi$-extension on the SF-I core or use of different heteroatoms on the xanthene scaffold may reveal even more red-shifted PSs, which can be excited by more penetrating light and has the potential to be used in in vivo PDT applications. Our work along these lines is in progress.

\section{ASSOCIATED CONTENT}

\section{Supporting Information}

The Supporting Information is available free of charge at https://pubs.acs.org/doi/10.1021/acsmedchemlett.1c00018.

Synthetic details; ${ }^{1} \mathrm{H},{ }^{13} \mathrm{C}$ NMR, and HR-MS spectra; details of photophysical characterization; ${ }^{1} \mathrm{O}_{2}$ trap experiments; additional photophysical measurements; details of cell culture and imaging experiments; additional cell culture experiments; and a table of $\mathrm{IC}_{50}$ values (PDF) 


\section{AUTHOR INFORMATION}

\section{Corresponding Authors}

Gorkem Gunbas - Department of Chemistry, Middle East Technical University, 06800 Ankara, Turkey; 이이.org/ 0000-0003-2279-3032; Email: ggunbas@metu.edu.tr

Safacan Kolemen - Department of Chemistry, Surface Science and Technology Center (KUYTAM), Boron and Advanced Materials Application and Research Center, and TUPRAS Energy Center (KUTEM), Koc University, 34450 Istanbul, Turkey; 이이이.org/0000-0003-4162-5587; Email: skolemen@ku.edu.tr

\section{Authors \\ Sultan Cetin - Department of Chemistry, Koc University, 34450 Istanbul, Turkey; (1) orcid.org/0000-0002-7719- 1154 \\ Zubeyir Elmazoglu - Department of Chemistry, Middle East Technical University, 06800 Ankara, Turkey \\ Osman Karaman - Department of Chemistry, Middle East Technical University, 06800 Ankara, Turkey \\ Hande Gunduz - Department of Chemistry, Koc University, 34450 Istanbul, Turkey}

Complete contact information is available at: https://pubs.acs.org/10.1021/acsmedchemlett.1c00018

\section{Author Contributions}

The manuscript was written by S.C., G.G., and S.K. Experiments were done by S.C., Z.E., O.K., and H.G. All authors have given approval to the final version of the manuscript.

\section{Funding}

Funding was received from The Scientific and Technological Research Council of Turkey (TUBITAK), Grant $117 \mathrm{Z} 901$. The research leading to these results has also received funding from the European Research Council (ERC) under the European Union's Horizon 2020 research and innovation program (Grant 852614).

\section{Notes}

The authors declare no competing financial interest.

\section{ACKNOWLEDGMENTS}

The authors acknowledge the researchers at Koc University Surface Science and Technology Center (KUYTAM) for fluorescence quantum yield measurements. G.G. thanks the Turkish Academy of Sciences (TUBA).

\section{ABBREVIATIONS}

PDT, photodynamic therapy; PS, photosensitizer; SF, siliconfluorescein; SF-I, iodinated silicon-fluorescein; NIR, nearinfrared; PBS, phosphate buffer saline; ISC, intersystem crossing; $\mathrm{H}_{2} \mathrm{O}_{2}$, hydrogen peroxide; DMSO, dimethyl sulfoxide; ADMDA, 2,2'-(anthracene-9,10-diyl)bis(methylene)dimalonic acid; MTT, 3-(4,5-dimethylthiazolyl2)-2,5-diphenyltetrazolium bromide; ROS, reactive oxygen species; PI, propidium iodide; $\mathrm{DCFH}_{2}$-DA, $2^{\prime}, 7^{\prime}$-dichlorofluorescein diacetate; HR-MS, high resolution mass spectrometry; OD, optical density; LED, light emitting diode; FITC, fluorescein isothiocyanate; IC50, half maximal inhibitory concentration

\section{REFERENCES}

(1) dos Santos, A. F.; de Almeida, D. R. Q.; Terra, L. F.; Baptista, M. S.; Labriola, L. Photodynamic Therapy in Cancer Treatment - an Update Review. J. Cancer Metastasis Treat. 2019, 5 (25), 83-103.

(2) Li, X.; Kolemen, S.; Yoon, J.; Akkaya, E. U. Activatable Photosensitizers: Agents for Selective Photodynamic Therapy. Adv. Funct. Mater. 2017, 27 (5), 1604053-1604064.

(3) Agostinis, P.; Berg, K.; Cengel, K. A.; Foster, T. H.; Girotti, A. W.; Gollnick, S. O.; Hahn, S. M.; Hamblin, M. R.; Juzeniene, A.; Kessel, D.; Korbelik, M.; Moan, J.; Mroz, P.; Nowis, D.; Piette, J.; Wilson, B. C.; Golab, J. Photodynamic Therapy of Cancer: An Update. Ca-Cancer J. Clin. 2011, 61 (4), 250-281.

(4) Shi, H.; Sadler, P. J. How Promising Is Phototherapy for Cancer? Br. J. Cancer 2020, 123 (6), 871-873.

(5) Huang, Z. A Review of Progress in Clinical Photodynamic Therapy. Technol. Cancer Res. Treat. 2005, 4 (3), 283-293.

(6) Abrahamse, H.; Hamblin, M. R. New Photosensitizers for Photodynamic Therapy. Biochem. J. 2016, 473 (4), 347-364.

(7) Vickerman, B. M.; O'banion, C. P.; Tan, X.; Lawrence, D. S. Light-Controlled Release of Therapeutic Proteins from Red Blood Cells. ACS Cent. Sci. 2021, 7, 93.

(8) Karges, J.; Kuang, S.; Maschietto, F.; Blacque, O.; Ciofini, I.; Chao, H.; Gasser, G. Rationally Designed Ruthenium Complexes for 1- and 2-Photon Photodynamic Therapy. Nat. Commun. 2020, 11 (1) DOI: $10.1038 / \mathrm{s} 41467-020-16993-0$.

(9) Luo, S.; Zhang, E.; Su, Y.; Cheng, T.; Shi, C. A Review of NIR Dyes in Cancer Targeting and Imaging. Biomaterials 2011, 32 (29), $7127-7138$.

(10) Atchison, J.; Kamila, S.; Nesbitt, H.; Logan, K. A.; Nicholas, D. M.; Fowley, C.; Davis, J.; Callan, B.; McHale, A. P.; Callan, J. F. Iodinated Cyanine Dyes: A New Class of Sensitisers for Use in NIR Activated Photodynamic Therapy (PDT). Chem. Commun. 2017, 53 (12), 2009-2012.

(11) Luo, S.; Tan, X.; Qi, Q.; Guo, Q.; Ran, X.; Zhang, L.; Zhang, E.; Liang, Y.; Weng, L.; Zheng, H.; Cheng, T.; Su, Y.; Shi, C. A Multifunctional Heptamethine Near-Infrared Dye for Cancer Theranosis. Biomaterials 2013, 34, 2244-2251.

(12) Shi, C.; Wu, J. B.; Pan, D. Review on Near-Infrared Heptamethine Cyanine Dyes as Theranostic Agents for Tumor Imaging, Targeting, and Photodynamic Therapy. J. Biomed. Opt. 2016, 21 (5), 050901.

(13) Jiao, L.; Song, F.; Cui, J.; Peng, X. A Near-Infrared Heptamethine Aminocyanine Dye with a Long-Lived Excited Triplet State for Photodynamic Therapy. Chem. Commun. 2018, 54 (66), 9198-9201.

(14) Tang, Y.; Xue, L.; Yu, Q.; Chen, D.; Cheng, Z.; Wang, W.; Shao, J.; Dong, X. Smart Aza-BODIPY Photosensitizer for Tumor Microenvironment-Enhanced Cancer Phototherapy. ACS Appl. Bio. Mater. 2019, 2 (12), 5888-5897.

(15) Watley, R. L.; Awuah, S. G.; Bio, M.; Cantu, R.; Gobeze, H. B.; Nesterov, V. N.; Das, S. K.; D’Souza, F.; You, Y. Dual Functioning Thieno-Pyrrole Fused BODIPY Dyes for NIR Optical Imaging and Photodynamic Therapy: Singlet Oxygen Generation without Heavy Halogen Atom Assistance. Chem. - Asian J. 2015, 10 (6), 1335-1343.

(16) Li, M.; Tian, R.; Fan, J.; Du, J.; Long, S.; Peng, X. A LysosomeTargeted BODIPY as Potential NIR Photosensitizer for Photodynamic Therapy. Dyes Pigm. 2017, 147, 99-105.

(17) Prieto-Montero, R.; Prieto-Castañeda, A.; Sola-Llano, R.; Agarrabeitia, A. R.; García-Fresnadillo, D.; López-Arbeloa, I.; Villanueva, A.; Ortiz, M. J.; de la Moya, S.; Martínez-Martínez, V. Exploring BODIPY Derivatives as Singlet Oxygen Photosensitizers for PDT. Photochem. Photobiol. 2020, 96, 458-477.

(18) Agazzi, M. L.; Ballatore, M. B.; Durantini, A. M.; Durantini, E. N.; Tomé, A. C. BODIPYs in Antitumoral and Antimicrobial Photodynamic Therapy: An Integrating Review. J. Photochem. Photobiol., C 2019, 40, 21-48.

(19) Kim, B.; Sui, B.; Yue, X.; Tang, S.; Tichy, M. G.; Belfield, K. D. In Vitro Photodynamic Studies of a BODIPY-Based Photosensitizer. Eur. J. Org. Chem. 2017, 2017 (1), 25-28. 
(20) Kamkaew, A.; Lim, S. H.; Lee, H. B.; Kiew, L. V.; Chung, L. Y.; Burgess, K. BODIPY Dyes in Photodynamic Therapy. Chem. Soc. Rev. 2013, 42 (1), 77-88.

(21) Li, L.; Chen, Y.; Chen, W.; Tan, Y.; Chen, H.; Yin, J. Photodynamic Therapy Based on Organic Small Molecular Fluorescent Dyes. Chinese. Chin. Chem. Lett. 2019, 30 (10), 16891703.

(22) Matsumoto, J.; Suzuki, K.; Yasuda, M.; Yamaguchi, Y.; Hishikawa, Y.; Imamura, N.; Nanashima, A. Photodynamic Therapy of Human Biliary Cancer Cell Line Using Combination of Phosphorus Porphyrins and Light Emitting Diode. Bioorg. Med. Chem. 2017, 25 (24), 6536-6541.

(23) Wen, Y.; Schreiber, C. L.; Smith, B. D. Dual-Targeted Phototherapeutic Agents as Magic Bullets for Cancer. Bioconjugate Chem. 2020, 31 (3), 474-482.

(24) Zhang, J.; Ning, L.; Huang, J.; Zhang, C.; Pu, K. Activatable Molecular Agents for Cancer Theranostics. Chem. Sci. 2020, 11 (3), 618-630.

(25) Gao, D.; Guo, X.; Zhang, X.; Chen, S.; Wang, Y.; Chen, T.; Huang, G.; Gao, Y.; Tian, Z.; Yang, Z. Multifunctional Phototheranostic Nanomedicine for Cancer Imaging and Treatment. Mater. Today Bio 2020, 5, 100035-100068.

(26) Yan, F.; Fan, K.; Bai, Z.; Zhang, R.; Zu, F.; Xu, J.; Li, X. Fluorescein Applications as Fluorescent Probes for the Detection of Analytes. TrAC, Trends Anal. Chem. 2017, 97, 15-35.

(27) Grimm, J. B.; Sung, A. J.; Legant, W. R.; Hulamm, P.; Matlosz, S. M.; Betzig, E.; Lavis, L. D. Carbofluoresceins and Carborhodamines as Scaffolds for High-Contrast Fluorogenic Probes. ACS Chem. Biol. 2013, 8 (6), 1303-1310.

(28) le Guern, F.; Mussard, V.; Gaucher, A.; Rottman, M.; Prim, D. Molecular Sciences Fluorescein Derivatives as Fluorescent Probes for PH Monitoring along Recent Biological Applications. Int. J. Mol. Sci. 2020, 21, 9217-9240.

(29) Buck, S. T. G.; Bettanin, F.; Orestes, E.; Homem-De-Mello, P.; Imasato, H.; Viana, R. B.; Perussi, J. R.; da Silva, A. B. F. Photodynamic Efficiency of Xanthene Dyes and Their Phototoxicity against a Carcinoma Cell Line: A Computational and Experimental Study. J. Chem. 2017, 2017, 7365263-73652671.

(30) Karaman, O.; Almammadov, T.; Emre Gedik, M.; Gunaydin, G.; Kolemen, S.; Gunbas, G. Mitochondria-Targeting SelenopheneModified BODIPY-Based Photosensitizers for the Treatment of Hypoxic Cancer Cells. ChemMedChem 2019, 14 (22), 1879-1886.

(31) Binns, T. C.; Ayala, A. X.; Grimm, J. B.; Tkachuk, A. N.; Castillon, G. A.; Phan, S.; Zhang, L.; Brown, T. A.; Liu, Z.; Adams, S. R.; Ellisman, M. H.; Koyama, M.; Lavis, L. D. Rational Design of Bioavailable Photosensitizers for Manipulation and Imaging of Biological Systems. Cell Chem. Biol. 2020, 27 (8), 1063-1072.

(32) Digby, E. M.; Rana, R.; Nitz, M.; Beharry, A. A. DNA Directed Damage Using a Brominated DAPI Derivative. Chem. Commun. 2019, 55 (67), 9971-9974.

(33) Egawa, T.; Koide, Y.; Hanaoka, K.; Komatsu, T.; Terai, T.; Nagano, T. Development of a Fluorescein Analogue, TokyoMagenta, as a Novel Scaffold for Fluorescence Probes in Red Region. Chem. Commun. 2011, 47 (14), 9971-9974.

(34) Kushida, Y.; Nagano, T.; Hanaoka, K. Silicon-Substituted Xanthene Dyes and Their Applications in Bioimaging. Analyst 2015, 140 (3), 685-695.

(35) Zhao, M.; Guo, Y. S.; Xu, W. N.; Zhao, Y. F.; Xie, H. Y.; Li, H. J.; Chen, X. F.; Zhao, R. S.; Guo, D. S. Far-Red to near-Infrared Fluorescent Probes Based on Silicon-Substituted Xanthene Dyes for Sensing and Imaging. TrAC, Trends Anal. Chem. 2020, 122, 115704115745 .

(36) Grimm, J. B.; Brown, T. A.; Tkachuk, A. N.; Lavis, L. D. General Synthetic Method for Si-Fluoresceins and Si-Rhodamines. ACS Cent. Sci. 2017, 3 (9), 975-985.

(37) Almammadov, T.; Atakan, G.; Leylek, O.; Ozcan, G.; Gunbas, G.; Kolemen, S. Resorufin Enters the Photodynamic Therapy Arena: A Monoamine Oxidase Activatable Agent for Selective Cytotoxicity. ACS Med. Chem. Lett. 2020, 11, 2491-2496.
(38) Fernandez, J. M.; Bilgin, M. D.; Grossweiner, L. I. Singlet Oxygen Generation by Photodynamic Agents. J. Photochem. Photobiol., B 1997, 37 (997), 131-140.

(39) Hirabayashi, K.; Hanaoka, K.; Takayanagi, T.; Toki, Y.; Egawa, T.; Kamiya, M.; Komatsu, T.; Ueno, T.; Terai, T.; Yoshida, K.; Uchiyama, M.; Nagano, T.; Urano, Y. Analysis of Chemical Equilibrium of Silicon-Substituted Fluorescein and Its Application to Develop a Scaffold for Red Fluorescent Probes. Anal. Chem. 2015, 87, 9061-9069.

(40) Halder, A.; Jethwa, M.; Mukherjee, P.; Ghosh, S.; Das, S.; Helal Uddin, A. B. M.; Mukherjee, A.; Chatterji, U.; Roy, P. LactoferrinTethered Betulinic Acid Nanoparticles Promote Rapid Delivery and Cell Death in Triple Negative Breast and Laryngeal Cancer Cells. Artif. Cells, Nanomed., Biotechnol. 2020, 48 (1), 1362-1371.

(41) Khan, K.; Valeri, N.; Dearman, C.; Rao, S.; Watkins, D.; Starling, N.; Chau, I.; Cunningham, D. Targeting EGFR Pathway in Metastatic Colorectal Cancer- Tumour Heterogeniety and Convergent Evolution. Crit. Rev. Oncol. Hematol. 2019, 143, 153-163.

(42) Yang, K.; Wen, J.; Chao, S.; Liu, J.; Yang, K.; Pei, Y.; Pei, Z. A Supramolecular Photosensitizer System Based on the Host-Guest Complexation between Water-Soluble Pillar[6]Arene and Methylene Blue for Durable Photodynamic Therapy. Chem. Commun. 2018, 54 (46), 5911-5914.

(43) Kuimova, M. K.; Yahioglu, G.; Ogilby, P. R. Singlet Oxygen in a Cell: Spatially Dependent Lifetimes and Quenching Rate Constants. J. Am. Chem. Soc. 2009, 131 (1), 332-340. 